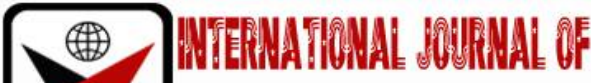

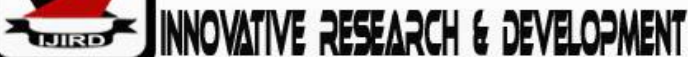

ISSN 2278-0211 (Online)

\section{Strategic Human Capital Management and Sustainable Development of Organisations: A Cognitive Mapping to Analyse the Role of Human Capital on Sustainable Development}

\begin{tabular}{c}
\hline Dr. Amembah A Lamu Amos \\
Lecturer, Department of Marketing Management, \\
Mwenge Catholic University, Tanzania \\
Blandina Kori \\
Assistant Lecturer, Department of Strategic Management, \\
Mwenge Catholic University, Tanzania
\end{tabular}

\begin{abstract}
:
This study focused on the strategic human capital management and sustainable development of organizations. It carried out a cognitive mapping and analyses different definitions and theories of human capital as described and conceptualized by the gurus of strategic human capital management and finally come up with a new concept to reflect the current era of innovation and sustainability by displaying human capital as the engine to sustainable development. Where, growth of individuals and availability for 'space' for exploration and utilization of the acquired skills results to sustainable growth of an economy, and sustainable development. While divergence of such practices may not yield sustainable businesses, as a result lead to retarded business growth and sustainable development. Further, the study redefines the concept of sustainable development to display a picture of a stable or unstable economy inour contemporary society. The study will integrate both environmental and social cultural aspects and put more emphasis on human capital management as catalysts for development. Secondary source of data will be used where various relevant empirically studies will be reviewed and critically analysed through contextual themes and narrative methods. The proposition that human capital role is highly significant in sustainable development will be the main subject for investigation. Specific objectives for investigation include: To find out the human capital development strategies for sustainability of organizations, to establish the human capital deployment strategies for sustainability of organizations, to investigate the extent investment on human capital strategies for sustainability of organizations. We therefore, argue that human capital has a significant contribution to sustainable development not only by conserving both environmentalists and social-cultural identity, but also by enhancing individual dimensional qualities.
\end{abstract}

Keywords: Human capital development, deployment, investment and sustainable development

\section{Introduction}

The concept of sustainable development is shaped by different scholars to mean the maintenance of the economic standing and advancement while protecting the long-term value of environment. According to Tomislav (2018) this concept refers to the balance between three pillars of sustainability, that is; the environmental sustainability, social sustainability and preservation of cultural identity. This therefore, implies that human capital determines the long-term sustainability, such that individual consciousness about the environmental changes and strong culture of development can be the most effective approach for ensuring sustainable future (Šlaus \& Jacobs, 2011). This means that, where the environment is well conserved, we expect the ecological equilibrium. This equilibrium brings about development which comes as a result of human creativity and innovation.

Essentially, it requires an effective strategic decision-making process for the organisation to form talent management, integrated with government and non-governmental policies to foster employability skills for the younger generation; with an aim of achieving high productivity and creativity capabilities. This will eventually support the economy to grow to a sustainable level, and in turn enhance human welfare and well-being i.e. sustainable development. Furthermore, organizations can consider harnessing individuals' qualitative dimensions such as knowledge production, vocational skills or culture in order to yield best services or income over time (Schuh, 2009). 


\subsection{Concept of Human Capital Management}

Human capital (HC) terminology was first conceptualized by Schultz in the early 1960s where he contends that human capital comprises individual knowledge, skills and ability in a given organization. However, this definition did not consider the important issue of value that is paramount in any capital investment, leading to revamping the same definition in 1981, where the same author (Schultz) indicated that HC includes all the human abilities which are either innate or acquired (McCracken, McIvor, Treacy, \& Wall, 2017). Some scholars indicate that HC alludes to the outcome of business sustainability, while others such as Thomas, Smith, and Diez (2013), defines HC as the 'people, their performance and their potential in the organisation'.

These definitions show a wide spectrum to explain the essence of HC from micro scholarship in psychology to macro scholarship in economics. Accordingly, the scholars contend that HC has a potential to be a source of superior organisation performance if integrated with human resource management (Boon, Eckardt, Lepak, \& Boselie, 2018). If well managed, human capital serves as a valuable resource which: captures, creates, and mobilizes knowledge and skills. This study borrows from these different definitions and develops the definitions by adding the element of inevitable change that come-by, in the process of implementation, hence enhancing economic growth and sustainability. Further, it is an essential mainstay for sustainable development due to its ability to support and harmonize all human resources related initiatives such as recruiting and on boarding, to payroll and benefits, to workforce performance management. The organisation therefore, harmonizes all the elements in order to gain a strategic fit, not only for the organisation, but also for economic sustainability and development and the achievement of millennium goals (Šlaus \& Jacobs, 2011). The value of implementation of HCM therefore, is that, it differentiates one economy from another, optimizes the workforce of an organisation, connects different human resource practices, hence cutting costs while maximizing productivity and improving the employees work life (Marimuthu, Arokiasamy \& Ismail, 2009).

\subsection{Concept of Sustainable Development}

The definition of sustainable development was coined by Bruntland Commission through their published report of 1987, whereby they stated that sustainable development is a 'development that meets the needs of the present without compromising the ability of future generations to meet their own needs' (Burton, 1987).This concept of sustainable development, focuses on the maintenance of economic advancement and progress which is not possible without assimilating the technological progress to address global challenges of jobs creation, but also advancing human capital through encouraging innovative skills.

Some scholars state that it is a rate of growth which can be maintained without creating other significant economic problems, especially for future generation. The concept here thus, tends to support safe growth economy to meet current and future basic needs and wealth creation. More definition emphasizes that for sustainable development to take place, economic development is a requirement. The concept further promotes growth of industries through digitization and investing in scientific research and safe innovation, with efficient and enough energy, but also free from pollution. This notion borrows from the wide wisdom of different people to benefit the world from all sorts of contribution, hence supporting the agenda nine (9) of sustainable development, which states that 'promote inclusive and sustainable industrialization and foster innovation' (Desa, 2016)

Furthermore, Strange and Bayley (2008) state that sustainable development is a way of changing the predominant world view to one that is more holistic and balanced, a process of applying the principles of integration across space and time to all decisions and a way of identifying solving social economic problems. In this study we argue that sustainable development is a way of managing human capital as the 'engine' of economic growth and sustainability.

\subsection{Concept of Talent Management}

The origin of talent comes as far as from the gospel of Mathew 25: 14 - 30, while in management this term became popular in 1990s and 2000s (Adamsen, 2016). In essence the concept talent management is the anticipation of required human capital for that plans to meet the needs for such capital (Mangusho, Murei, \& Nelima, 2015). The concept became popular between 1997 and 2001 through a book written by McKinney's but exact source is not clearly established (Dimitrov, 2018).

Byrne (2013) agrees that talent management is about strategy of retaining, human resource management, human resource development, human resources succession. It is a process of hiring the right people and enabling each of them to maximize individual talents. The major aim for talent management is to build strong work-force in an organisation. Baqutayan (2014) also states that talent management is crucial source for competitive advantage, sustains performance, enhances growth and brings about innovation. Düren, (2010) states that, talent management in an organisation is meant to develop team capabilities through nurturing individual capabilities. Other scholars identify talent management as talent development, latent deployment process and training of the employees, in that, this practice is involved in developing employment skills, provide learning opportunities, and secure tools for staff to advance their overall careers ( 0 'riordan, 2017). Further, the process involves talent deployment through identification of talent to fill critical workforce gaps (Devos, 2008).

\section{Statement of the Problem}

Other scholars identify talent management as talent development, latent deployment process and training of the employees, in that, this practice is involved in developing employment skills, provide learning opportunities, and secure tools for staff to advance their overall careers (O'riordan, 2017). Further, the process involves talent deployment through identification of talent to fill critical workforce gaps (Devos, 2008) 
Despite the booming economies in Africa there's shortage of talents, which forces the rapid growth in Africa's key economic hubs to search for talents to fill critical roles. Research indicate that big international organizations in African are forced to buy $70 \%$ of talents into their Africa-based operation, with only $30 \%$ coming from the internal or local sources. More research indicates that by 2022, not less than $54 \%$ of all employees will require significant re-skilling or up skilling. Out of these, $35 \%$ will require additional training of up to six months, $9 \%$ will require a period of about 12 months, while $10 \%$ may require training period of more than one year (Leopold, Ratcheva \& Sahidi, 2018).

On the other hand, a contradicting report indicated that $50 \%$ of the young graduates in Africa do not find appropriate jobs for their profession, or rather they find lower quality jobs for their qualifications. The required skills for employability in most organisation, currently range from analytical thinking, innovativeness, active learning and learning strategies, which inadequate in searching organizations (De Mel, Elder, \& Vansteenkiste, 2013). However, studies indicate that most of the organizations find HCM as an expensive activity, hence struggling to keep-up with the demand for highly skilled labour force.

The gap between the requirement for high skilled labour force and the current labour available skills in Africa, therefore invites a big question on how the current labour force framework is prepared to meet the demands for economic development and sustainability, which can only be possible through deploying the right labour force on the right jobs.

Therefore, this study investigates the human capital management in African industries.।

\section{Study Objectives}

- To evaluate the extent of human capital development towards the sustainability of organizations

- To find out the human capital development strategies for sustainability of organizations.

- To establish the human capital deployment strategies for sustainability of organizations.

- To investigate the extent investment on human capital strategies for sustainability of organizations.

\section{Theoretical Framework}

\subsection{Ecological Systems Theory}

This study adopted the ecological system theory to explain the relationship between human capital and sustainable development. The Ecological Systems theory or rather Human Ecological Theory explains how human development is influenced by different types of environmental systems. This theory was first known as the ecological framework for human development which was introduced by Bronfenbrenner in 1970s as a conceptual model and later became a theoretical model in the 1980s (Rosa, \& Tudge,2013). The aim of Bronfenbrenner was to apply this theory to human development. Accordingly, Bronfenbrenner postulated that in order to understand human development, the entire ecological system in which growth occurs needs to be taken into account (Ebersohn \& Bouwer, 2015).

Sustainable development concept employs this theory to explain the relationships between ecological system, economic development and social-cultural systems. The interaction, interrelation and dependences of human activities forms a system bounded structure, where things influence one another within a whole scenario, hence completing an ecological model (Brunner and Urenje 2012). The human capital situated within the organisation, and well-managed, is examples of a system build through employees' career development, deployment opportunities and training to acquire necessary skills. Thus, once individuals are provided with relevant career development, talents deployment and training for the right jobs they become key agents for economic development, hence the 'engine' for sustainable development (Desa, 2008).

As noted, Bronfenbrenner ecological model examines the nature of human being, to development and create an environment suitable for their survival. This is perfectly related to how human being is an absolute contributor or part of ecological system theory and a sustainable development concept. In this study we argue that human development is economic development which in turn leads to economic development.

\section{Conceptual Framework}

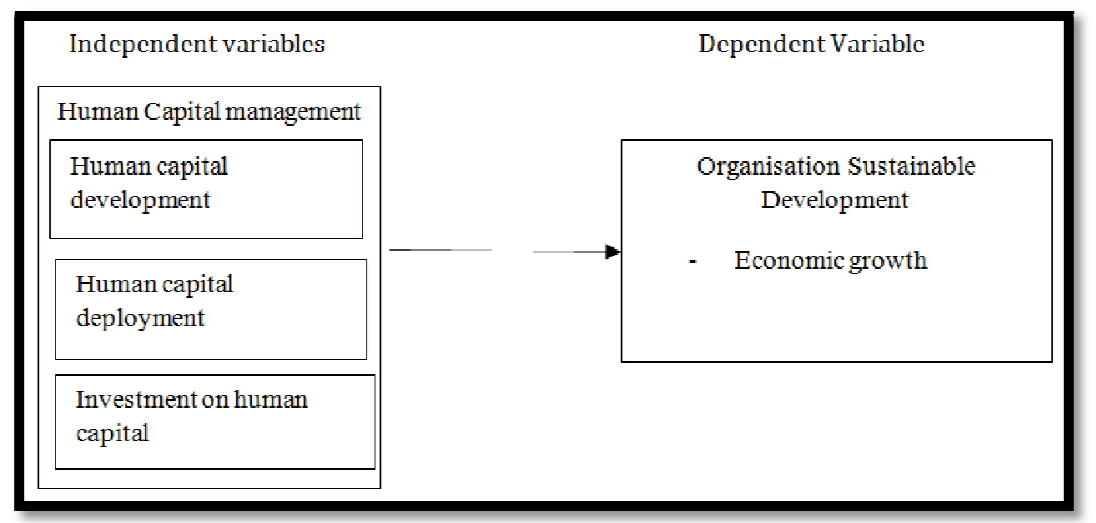

Figure 1. Researcher's Own Construction, (2020)

The conceptual framework above indicate that human capital management (Independent variable) comprise components such as employee's human capital development, human capital investment on deployment and human capital, 
which results to sustainable development (dependent variable) of the business organisation, who's outcome is economic sustainability of organisation and the achievement of millennium goals 2030 for sustainable development.

\section{Literature Review}

\subsection{Human Capital Development and Organisation Sustainable development}

Current economic growth requires human capital as an organizational asset to achieve superior business results, for sustainable development; because a paradigm shift in view of human position within organizations indicated that people are vital factors of production and the main diver of organizationalgrowth. However, the researcher argues that despite these evidences, there is still a poor understanding and implementation of this process in some organizations (Muka \& Efendy, 2018).

Boztous, Aksoylu and Şentürk Ulucak, (2016) carried out a study on the role of human capital in economic growth. This was a cointegrated study which utilized both empirical and theoretical data, where causality tests were carried out using data of Turkey for the period 1961-2011. The study was set to investigate the relationships between human capital and economic growth. Findings indicated a significant relationship between human capital and economic growth (Boztosun, Aksoylu, \& Şentürk Ulucak, 2016). Another study conducted in Rumania from the energy sector set to investigate the role of human resources in sustainable development. Results indicated that Romania has an increase in labour productivity due to utilization of human capital. Accordingly, the researchers concluded that there's needy for reforms on education to recognize vital human role in the economy.

Ekperiware, Olatayo and Egbetokun (2017) in Nigeria, on human capital and sustainable development, sort to investigate how economic growth can suffice environmental degradation. The study revealed that an increase in human capital development reduces environmental degradation and increases in economic growth. Accordingly, the researchers concluded that human capital formation leads to sustainable economic growth while reducing environmental degradation. Hamadamin and Atan (2019) carried out a study to examine the influence of the strategic human resource management practices on the achievement of a sustainable competitive advantage, and evaluate the mediating role of human capital development; this was an empirical study where data was collected using questionnaires. Findings revealed a positive influence on strategic human resource management on the sustainability of competitive advantage, and that human resource positively influenced human capital development and sustainable competitive advantage. The recommended a theoretical study on the same area.

\subsection{Human Capital Deployment and Organisation Sustainable Development}

Human capital deployment is a strategic tool for utilizing the organisation employees' knowledge, skills, and talents for the good of the company. This depends on the company's concerns on the returns on capital market's expectations for their growth and understanding where they are in the industrial lifecycle. Depending on the needs of the organisation, the processes are basically meant to attract, develop, motivate, and retain productive, and or engaged employees, with a purpose of creating superior performance for a sustainable organisation.

Ma, Zhai, Zhong and Zhang (2019) study on human capital deployment, focusing on innovation found that both task-related training and employee's participation improve firm innovation in terms of the commercial success of new products development and percentage of firm revenue from newly developed products. This was a survey carried out in 304 manufacturing firms across 13 economies. The findings of this study shed light on the importance of human capital deployment globally to all managers.

A study carried out by Latukha (2018) confirmed that human capital deployment has a positive contribution towards company's performance. This was an empirical study conducted in Russian companies. Attention was paid to the analysis of talent development programs that were used to develop talents in Russia and the factors that influence the creation and implementation of human capital deployment thereof. Accordingly, results showed that talent development has a significant influence on organization's growth and development. On the other hand, scholars suggest that more researches should be conducted on how to develop inflow of talent that is cost effective, and its impact on business outcomes. This is because there are evidences that organizations still lack strength in enhancing or creating a culture that stimulates innovativeness without being cautious on the opportunity cost. More suggestions are that organizations should ensure maximum use of human capital, which is only be possible when they focus on strategic objective of human capital deployment by placing an adequate budget for the same (Maycock \& Ikuomola, 2015).

Efendy (2018) suggest that since human is not just a factor of production, but also a valuable asset to an organisation, they must be developed and humanized. This means, human must he handles with care and motivated to produce. That human cannot be handled as an object or non-living thing. This was a descriptive analysis case study in a health science school in Indonesia. The research focused on implementation of human capital management in human resources department. It is therefore important that organization's come up with all possible approaches, which are compatible with the firm's philosophy of business, purpose, goals, and objectives, and choose the best way to develop their employees for better performance of their organizations, and add value to economic development.

\subsection{Investment on Human Capital and Sustainable Development}

Recent research show that, globally, the development of knowledge economies, and emergence of the BRIC countries (Brazil, Russia, India and China) as economic power houses, are faced with critical issues on talent shortages in their companies, indicating an in equilibrium as regard to supply and demand for required talents (Ford, Harding, \& Stoyanova Russell, 2010).Chordiya, Pawar, Chordiya identifies investment on human capital as strategic important, since 
through human capital management in the organizations develop strong leadership team that is vital for competitive advantage and growth, which have a direct impact on sustainable development. Baquatayan (2014) found that human capital management enhance business strategies that modifies organisation activities to gain high proficiency and improved organisation performance, leading to the achievement sustainable development.

A study of contemporary role of human capital for building a sustainable culture in organizations reviled that investment on human capital on enhance skills of individuals, build organisation capabilities, hence providing a source for building good culture of performance in organizations and a sustainable development culture in the society. This was a qualitative research carried out in Indian industries. Another research by Mwila and Turay (2018) on augmenting talent management for sustainable development in Africa discovered that current challenges faced by South Africa businesses would only be solved through talent management practices.

The study further argues that 'there may be scope for the augmentation of current practice in psychometric testing which may address a plethora of problem currently defining the talent context in African businesses'. This was a narrative inquiry paper conducted in 2016 on an expert panel of talent managers in businesses bases in South Africa. Likewise, some researches indicate that companies can only succeed in the long-term if they recruit and motivate people who are able to display different talents and shape the future of their organisation, which in turn add value to the sustainable development and the achievement of the millennium goals of 2030 (World Economic Forum, 2015).

Other researcher argues that the only and best way to engage employees in the sustainable development is through training of individual staff in the organisation. 'A series of environmental education and awareness training programmes of The Hongkong and Shanghai Banking Corporation Limited (HSBC) carried out by Law, Hill and Hau (2017) was used as a case study to assess how learning transfers through nature-based environmental education and awareness training and to investigate the possible outcomes of providing nature-based training to employees.' The study used evaluation of outcome of after training method, where attitudes, behaviour and environmental knowledge were tested using retrospective post-and then-test questionnaires. The results indicated that the employees who joined these programmes gained knowledge and changed their values and behaviour hence providing better results to the organisation (Law, Hills, \& Hau, 2017).

More researcher agree that sustainable development is a compelling idea worldwide, hence forcing managers of all levels in organizations, to develop structures that supports change. This only happens through encouraging all members of the company to act as enthusiastic agents of change, whereby personnel value takes precedence (World Business Council for Sustainable Development. (2004)). In essence, in leading companies, these managers are expected to act as agents of change: to develop the structures, systems, ways of working and personal values that will support the organisation's sustainable development objectives; and to encourage others in the company to act as enthusiastically together (World Economic Forum, 2015).

According to Ji, Huang, Liu, Zhu and Cai (2012) employees training consistent with demands have a positive effect on firms' performance in sustainable development, and that there is a positive relationship between a firm's environment attitude and its performance in sustainable development. This is was an empirical study carried in manufacturing firms in both South and North China. Further this study showed that better results were obtained by taking into account the human resources management practices such employees training. The study further suggests that employee training may also have a positive direct effect on firms' performance and enhance sustainable development.

\section{Conclusion}

The study identified human capital as entirety of talents, qualifications, skills and accumulated experiences that contribute to individual ability to deliver economic benefits. It is an investment therefore, that brings in return to the organisation. Further an overview of human capital management and its contribution to sustainable development, showed that human capital management enhances employability qualities on individuals or employees in organizations, and that it involves awide range of human resources management strategies needed to properly develop an organisation's workforce, while elevating their worth. Its foundation encompasses core skills such as; access to education, availability of training opportunities, motivation, ability to embrace continuous learning and support in doing so, and recognition of acquired skills.

As a result, organizations cannot function successfully without applying policies to support the human capital management. Thus, to get the best out of its employees, organizations should work hard to ensure re-skilling of their employee to acquire more than average skills for competitive advantage. Accordingly, this is the only way to achieve sustainable development required by the millennium goals agenda 2030. Consequently, the organizations that fail to reskill will risk facing obsolescence in skills of their workforce. Moreover, the art of re-skilling re-sharpens an individual's talents hence making an impact on performance and demonstrates the highest levels of potential for future of the economy.

In conclusion the analysis in this paper showed that there were several areas of human capital management that cause sustainable development. We therefore argue that, human capital management is not only about recruiting, managing, developing and optimizing the human resources of an organisation, but also is a synergy of talent management, which comprise talent development, talent deployment and training of employee. This combines leadership ability, emotional maturity, communication skills, ability to attract and inspire other talented people, to achieve superior results in organisation and sustainable development. This being a literature review paper, more research can be done on the same using empirical data to test the hypothesis. 


\section{References}

i. Adamsen, B. (2016). The Need for Talent: The Origins of Talent Management in Business and Sports. In Demystifying Talent Management (pp. 40-61). Palgrave Macmillan, London.

ii. Angheluță, S. P., Margina, O., Zaharia, A., \& Arionesei, G. (2014). The Role of Human Resources in Sustainable Development of The Energy Sector. Ecoforum Journal, 3(1), 1.

iii. Baqutayan, S. M. S. (2014). Is talent management important? An overview of talent management and the way to optimize employee performance. Mediterranean Journal of Social Sciences, 5(23), 2290.

iv. Boon, C., Eckardt, R., Lepak, D. P., \& Boselie, P. (2018). Integrating strategic human capital and strategic human resource management. The International Journal of Human Resource Management, 29(1), 34-67.

v. Boztosun, D., Aksoylu, S., \& Şentürk Ulucak, Z. (2016). The role of human capital in economic growth. Economics World, 4(3), 101-110.

vi. Brunner, W. \& Urenje, S. A Holistic Approach to Environmental and Sustainability Education, (SWEDESD).

vii. Burton, I. (1987). Report on reports: Our common future: The world commission on environment and development. Environment: Science and Policy for Sustainable Development, 29(5), 25-29.

viii. Byrne, H (2013). Talent Management and succession Planning, Human Resources Strategies to Avoid a Skill Gap Forming During a Recessional Climate.

ix. Chordiya, K. D., Pawar, K. M., Chordiya, K. D., \& No, M. Talent Management for Sustainable Development.

X. De Mel, S., Elder, S., \& Vansteenkiste, M. (2013). Labour market transitions of young women and menin Liberia. ILO.

xi. Desa, U. (2008). Achieving Sustainable Development and Promoting Development Cooperation.

xii. Desa, U. N. (2016). Transforming our world: The 2030 agenda for sustainable development.

xiii. Dimitrov, K. (2018). Talent management-an etymological study. arXiv preprint arXiv:1810.02615.

xiv. Düren, A. Z. (2010). Nurturing the leader: talent management in organizations. Journal of Naval Sciences and Engineering, 6(2), 89-98.

$x v$. Efendy, H. (2018). Implementation of Human Capital Management in HR Section of the Hang Tuah School of Health Science (STIKES) Pekanbaru, International Journal of Human Resource Studies ISSN 2162-3058 2018, Vol. 8, No. 1

xvi. Ekperiware, M. C., Olatayo, T. O., \& Egbetokun, A. A. (2017). Human Capital and sustainable development in Nigeria: How can economic growth suffice environmental degradation? (No. 2017-29). Economics Discussion Papers.

xvii. Ebersohn, S., \& Bouwer, A. C. (2015). A bio-ecological interpretation of the relationship challenges in the context of the reconstituted family. South African Journal of Education, 35(2), 1039.

xviii. Emas, R. (2015). The concept of sustainable development: definition and defining principles. Brief for GSDR, 2015.

xix. Ford, J., Harding, N., \& Stoyanova Russell, D. (2010). Talent management and development. An overview of current theory and practice.

xx. Ji, L., Huang, J., Liu, Z., Zhu, H., \& Cai, Z. (2012). The effects of employee training on the relationship between environmental attitude and firms' performance in sustainable development. The International Journal of Human Resource Management, 23(14), 2995- 3008.

xxi. Hamadamin, H. H., \& Atan, T. (2019). The Impact of Strategic Human Resource Management Practices on Competitive Advantage Sustainability: The Mediation of Human Capital Development and Employee Commitment. Sustainability, 11(20), 5782.

xxii. Kucharčíková, A., Tokarčíková, E., \& Blašková, M. (2015). Human capital management-aspect of the human capital efficiency in university education. Procedia-social and behavioral sciences, 177, 48-60.

xxiii. Latukha, M. O. (2018). Talent development and a firm's performance: Evidence from Russian companies. Journal of General Management, 43(2), 51-62.

xxiv. Law, M. M. S., Hills, P., \& Hau, B. C. H. (2017). Engaging employees in sustainable development-a case study of environmental education and awareness training in Hong Kong. Business Strategy and the Environment, 26(1), 84-97.

xxv. Leopold, T. A., Ratcheva, V. S., \& Sahidi, S. (2018). The Future of Jobs Report 2018, Insight Report. Centre for the New Economy and Society.

xxvi. Li, F. F., \& Devos, P. (2008). Talent management: art or science? The invisible mechanism between talent and talent factory.

xxvii. Ma, L., Zhai, X., Zhong, W., \& Zhang, Z. X. (2019). Deploying human capital for innovation: A study of multicountry manufacturing firms. International Journal of Production Economics, 208, 241-253.

xxviii. Mangusho, Y. S., Murei, R. K., \& Nelima, E. (2015). Evaluation of talent management on employee's performance in beverage industry: A case of delmonte Kenya Limited. International Journal of Humanities and Social Science, 5(8), 191-199.

xxix. Marimuthu, M., Arokiasamy, L., \& Ismail, M. (2009). Human capital development and its impact on firm performance: Evidence from developmental economics. Journal of international social research, 2(8).

xxx. Maycock, E. A., \& Ikuomola, O. A. (2015). Learning and talent development: a review in context. International Journal of Advanced Research in Engineering \& Management (IJAREM), 98-111.

xxxi. McCracken, M., McIvor, R., Treacy, R., \& Wall, T. (2017). Human capital theory: assessing the evidence for the value and importance of people to organizational success. 
xxxii. Mwila, N. K., \& Turay, M. I. S. (2018). Augmenting talent management for sustainable development in Africa. World Journal of Entrepreneurship, Management and Sustainable Development, 14(1), 41-49.

xxxiii. O'riordan, J. (2017). The practice of human resource management. Research Paper, 20.

xxxiv. Rizvi, Y. S., \& Garg, R. (2017). A Study of the Contemporary Role of Talent Management in Building Sustainability Culture in Organizations. Researchers World, 8(2), 90.

xxxv. Rosa, E. M., \& Tudge, J. (2013). Urie Bronfenbrenner's theory of human development: Its evolution from ecology to bioecology. Journal of Family Theory \& Review, 5(4), 243-258.

xxxvi. Schuh, G. E. (2009). Human capital for sustainable economic development. Dimensions of sustainable development. Oxford: EOLSS Publications, 74-91.

xxxvii. S Šlaus, I., \& Jacobs, G. (2011). Human capital and sustainability. Sustainability, 3(1), 97-154.

xxxviii. Strange T. \& Bayley A. (2008). Sustainable Development, Linking economy, Society, Environment, OECD, Insights.

xxxix. Souleh, S. (2014). The Impact of Human Capital Management on the Innovativeness of Research Center. The case of Scientific Research Centers in Algeria. International Journal of Business and Management, 2 (4), 8096.

xl. Thomas, H., Smith, R.R. and Diez, F. (2013) Human Capital and Global Business Strategy. New York: Cambridge University Press.

xli. Tomislav, K. (2018). The Concept of Sustainable Development: From its Beginning to the Contemporary Issues. Zagreb International Review of Economics \& Business, 21(1), 67- 94.

xlii. World Business Council for Sustainable Development. (2004). Mobility 2030: meeting the challengesto sustainability. World Business Council for Sustainable Development. 